\title{
Obstructive accessory mitral valve tissue in an adult patient: a case report
}

\author{
Mahmoud Mardenli', Abdulla Samman ${ }^{1 *} \mathbb{D}$, Hussein Alkanj ${ }^{2}$ and Amal Babi
}

\begin{abstract}
Background: Accessory mitral valve tissue is a rare congenital anomaly that is commonly diagnosed in early childhood and rarely in adulthood. It is usually asymptomatic. However, it may cause left ventricular outflow tract obstruction in a way that mimics various other causes of obstruction.

Case summary: A 72-year-old Caucasian man complained of chest discomfort and exertional dyspnea for 3 months. There were no specific findings from a physical examination except systolic murmur. Transthoracic echocardiography demonstrated a mass on the mitral valve extending to the intraventricular septal, raising the pressure gradient flow across the aortic valve. Transesophageal echocardiography showed parachute-like tissue connected to the anterior leaflet of the mitral valve causing left ventricular outflow tract obstruction. During the surgery preparation period, he underwent coronary angiography and computed tomography to study the anatomy surrounding the mass. After surgery, biopsy showed non-specific findings.

Conclusion: When facing a case of aortic valve stenosis, accessory mitral valve tissue should be kept in mind as one of the possible underlying causes despite its rarity. Although it is simple and noninvasive, echocardiography remains the best diagnostic procedure to make the correct decision about management and to define the golden time for surgical intervention.
\end{abstract}

Keywords: Accessory mitral valve tissue, Left ventricular outflow tract obstruction, Echocardiography

\section{Background}

Accessory mitral valve tissue (AMVT) is a rare congenital cardiac malformation that sometimes causes left ventricular outflow tract (LVOT) obstruction and is commonly associated with other congenital cardiac anomalies [1]. It is usually present in childhood causing LVOT obstruction. Such an obstruction leads to chest pain, effort syncope, or recurrent transient ischemic attack/stroke. The number of adults affected by such a disease is one per 26,000 echocardiograms [2].

The first case of this rare condition was described in the literature in 1842 [3], whereas the first surgical treatment was described in 1963 [4]. The majority of patients who were reported to have varying degrees of LVOT obstruction were diagnosed with AMTV during the first 10 years of their life. However, LVOT was rarely detected in adulthood [5].

\footnotetext{
* Correspondence: abdullasamman@gmail.com

${ }^{1}$ Cardiology Department, Aleppo University Hospital, Aleppo, Syria

Full list of author information is available at the end of the article
}

Here is a case report of an adult patient with AMVT, whose disease developed a severe obstruction of LVOT.

\section{Case presentation}

A 72-year-old Caucasian man, suffering chest pain, visited our emergency department after being diagnosed as having dyspnea. The dyspnea started 3 months ago and deteriorated the week before visiting our emergency department. His dyspnea occurred with moderate exertion without any associated symptoms. His chest pain was atypical with some parietal characteristics. He was a heavy tobacco smoker with no medical history and with no chronic medications prescribed. However, hypertension seemed to have run in his family.

A physical examination revealed severe systolic murmur in the aortic area radiating toward the left parasternal space, becoming fainter at the apex. Blood pressure was symmetric, measuring $155 / 75 \mathrm{mmHg}$, pulse rate was 95 beats per minute (bpm). Lungs were clear on auscultation without crackles or abnormal sounds. A chest $\mathrm{X}$-ray showed normal cardiac silhouette and aortic arch,

(c) The Author(s). 2019 Open Access This article is distributed under the terms of the Creative Commons Attribution 4.0 International License (http://creativecommons.org/licenses/by/4.0/), which permits unrestricted use, distribution, and 


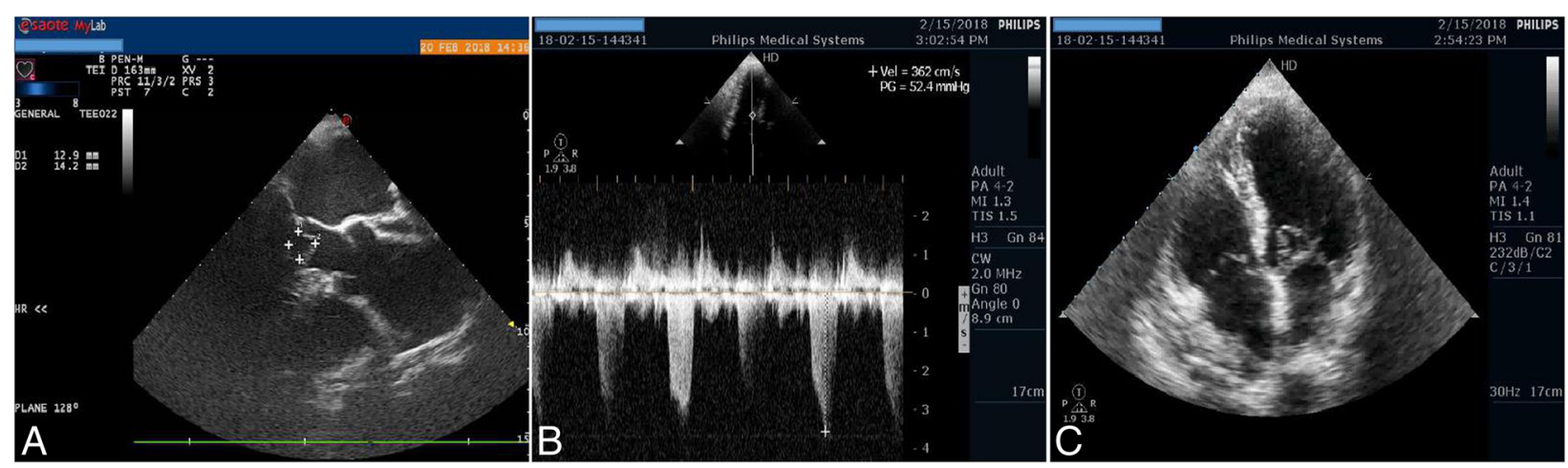

Fig. 1 a Transesophageal echocardiography demonstrated tissue dimensions and location. b Transthoracic echocardiography pressure peak gradient measured by continuous wave Doppler across left ventricular outflow tract. c Transthoracic echocardiography apical four-chamber view showed the relation between the accessory mitral valve tissue and the anterior leaflet of the mitral valve

and both lungs were clear and expanded with no infiltrates or pleural effusions. An electrocardiogram showed non-specific changes with $\mathrm{T}$ wave inversion on lateral leads and horizontal ST segment depression on $\mathrm{V}_{4-6}$.

He was admitted to the coronary care unit to follow up on the process of examining his body functions. Transthoracic echocardiography (TTE) revealed an oval-like tissue with clean margins attached to the proximal portion of the anterior leaflet of the mitral valve causing LVOT occlusion during systole. The gradient pressure through LVOT measured $55 \mathrm{mmHg}$, without organic lesion in the aortic cusps. The left ventricle wall motion was normal. Dimensions at systolic and diastolic phases were normal. Pulmonary pressure was $18 \mathrm{mmHg}$. No other cardiac anomalies were present (Fig. 1b, c, Additional file 1: Video S1).

To obtain more detailed information, transesophageal echocardiography (TEE) was performed. This revealed a parachute-like structure (measuring $13 \times 14 \mathrm{~mm}$ ) attached to the proximal portion of the anterior leaflet of the mitral valve causing LVOT obstruction (Fig. 1a, Additional file 2: Video S2).

Metoprolol tartrate $50 \mathrm{mg}$ twice daily was prescribed for our patient until the scheduled surgery. During hospitalization, multi-slice computed tomography (MS-CT) scan was performed. It emphasized the presence of the abnormal mass and its dimensions and location (Fig. 2).

He underwent coronary catheterization before the surgery. The angiography showed ostial lesion and severe stenosis in the mid left anterior descending (LAD) in addition to $80 \%$ stenosis in circumflex (CX), and the right coronary artery (RCA) had multi-sequential lesions beginning from the first segment (Fig. 3).

The surgery was delayed for a month due to a huge workload in the surgical department at that time. Since the case was rare and not fully understood by surgeons, it was classified as "cold case" in comparison to other on-list cases. Later on, our patient underwent coronary artery bypass graft (CABG) surgery and the abnormal tissue was surgically removed. The biopsy was sent to

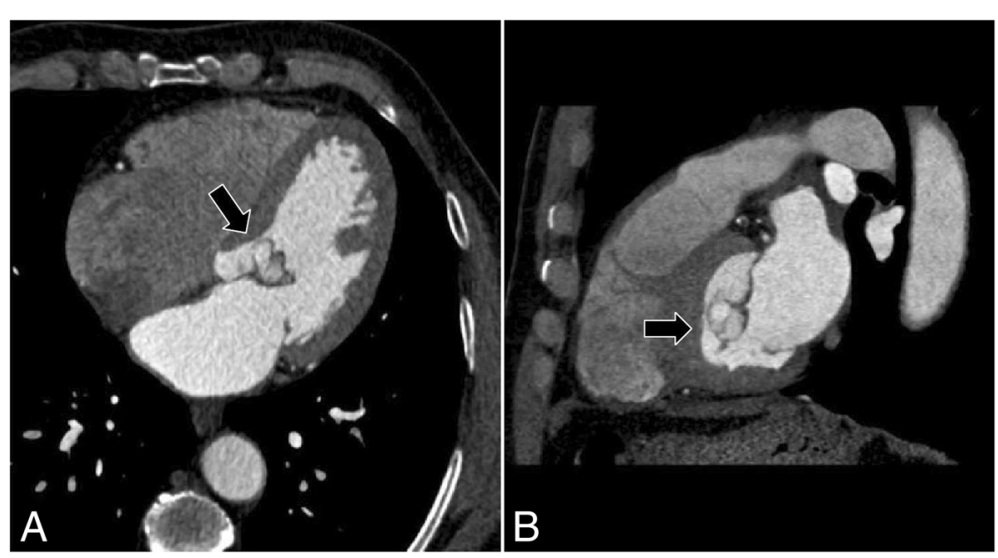

Fig. 2 Multi-slice computed tomography. a Axial section demonstrated the mass. b Sagittal section illustrated the location of the mass and relation to aortic valve. The arrows refer to the left ventricle output where the mass was found 


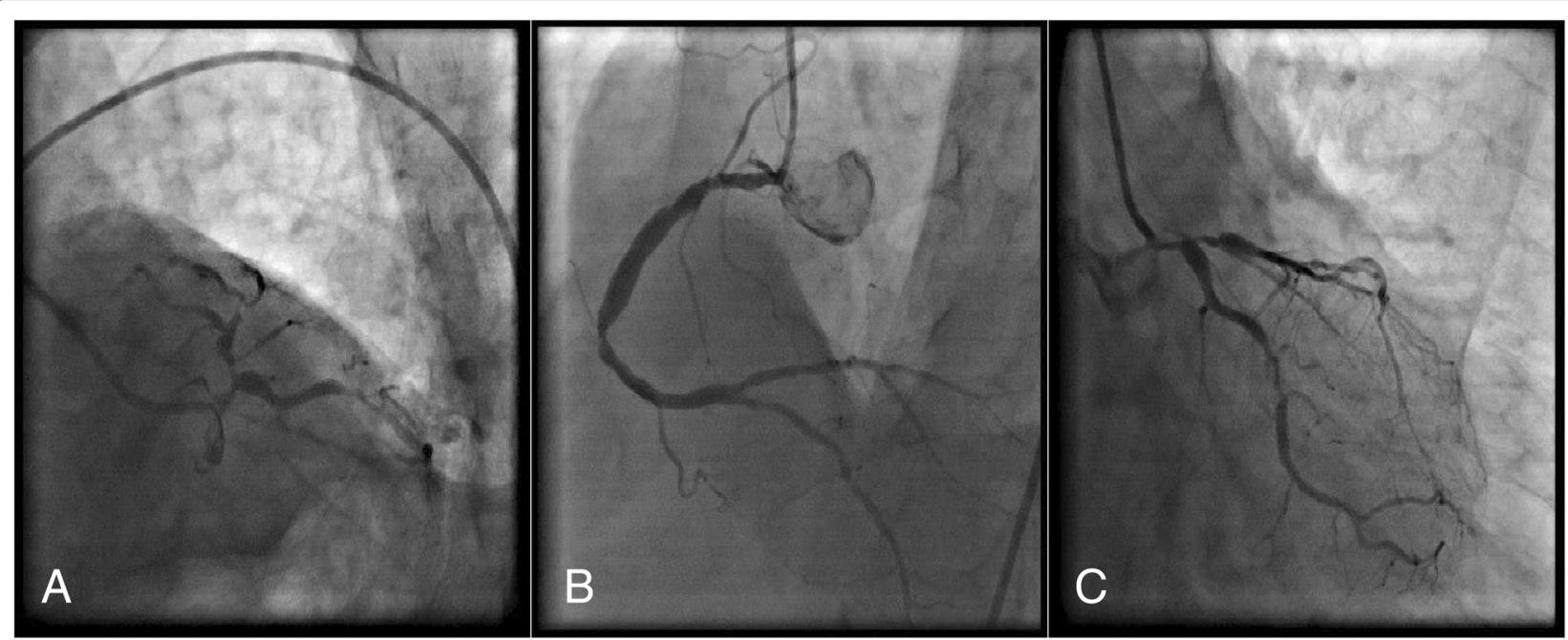

Fig. 3 Coronary catheterization. a Spider view showed ostial left anterior descending lesion. b Multi-sequential right coronary artery lesions. c Right anterior oblique-caudal view showed severe stenosis in circumflex

the pathology laboratory for further investigation (Fig. 4). The pathology report indicated a pure fibrous tissue with non-differentiated cells. Two weeks later, another TEE was done to assess the flow across the LVOT and the pressure gradient (PG) was normal. No residue of the abnormal tissue was seen. A timeline is shown in Table 1.

\section{Discussion}

AMVT in adults is very rare and can mimic various causes of LVOT obstruction. While most cases are diagnosed in childhood, rarely do these cases happen in adulthood. Less than $30 \%$ of these anomalies occur in adults, two thirds of the patients were associated with other cardiac anomalies, and symptoms of LVOT obstruction developed early in the neonatal or childhood periods [1]. Although the underlying cause is still uncertain, it is suggested that AMVT results from an incomplete

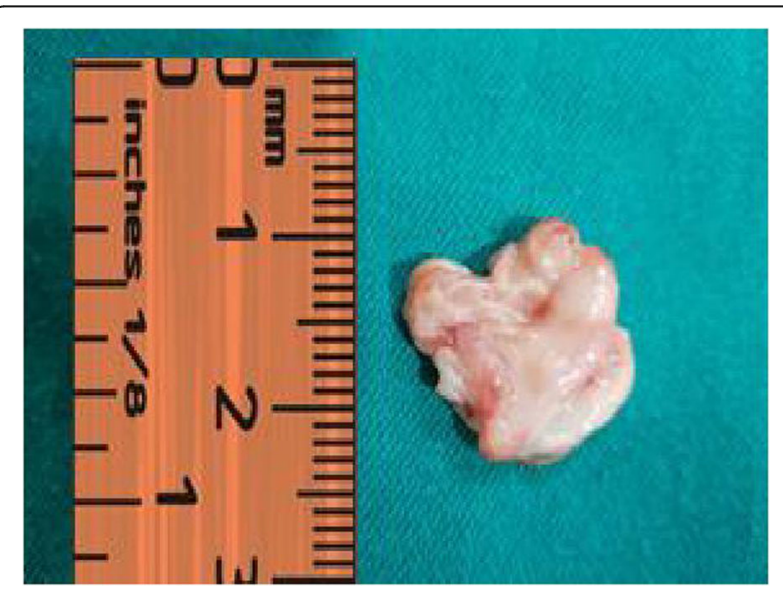

Fig. 4 Gross view of the tissue after surgery separation of the mitral valve from the endocardial cushion during cardiac development during embryogenesis [6]. Patients with AMVT anomaly may be asymptomatic but more frequently experience palpitations and fatigue [7].

Patients with AMVT become symptomatic when the mean gradient across the LVOT is more than $50 \mathrm{mmHg}$ [2]. Severe obstruction is defined when LVOT gradient is over $50 \mathrm{mmHg}$, while the obstruction is defined as mild when the gradient is less than $31 \mathrm{mmHg}$ [1]. AMVT has been variably described as sail-shaped, sac-like, balloon-like, parachute-like, and leaflet-like, or as a sheet, membrane, or pedunculated mass [8].

Despite the rarity of AMVT in adults, it should be kept in mind as part of the differential diagnosis of

Table 1 Organized timeline

\begin{tabular}{|c|c|}
\hline $\begin{array}{l}\text { Three months } \\
\text { earlier }\end{array}$ & $\begin{array}{l}\text { Non-specific symptoms started (chest discomfort and } \\
\text { exertional dyspnea) }\end{array}$ \\
\hline Day 0 & Visiting ER and admission to CCU \\
\hline Day 1 & $\begin{array}{l}\text { Stabilizing vital signs and controlling symptoms/ } \\
\text { Management with metoprolol and } \mathrm{O}_{2}\end{array}$ \\
\hline Day 2 & TTE discovered a suspicious mass \\
\hline Day 7 & TEE emphasized the presence of accessory tissue \\
\hline Day 14 & $\begin{array}{l}\text { Multi-slice CT studied the relation between the tissue } \\
\text { and its neighboring anatomy and provided a primary } \\
\text { impression of the coronary tree }\end{array}$ \\
\hline Day 25 & $\begin{array}{l}\text { Coronary catheterization demonstrated multi-vessel } \\
\text { disease with no associated anomaly }\end{array}$ \\
\hline Day 40 & CABG and surgical removal of the mass \\
\hline Day 50 & $\begin{array}{l}\text { Biopsy showed fibrous tissue and TEE clarified normal } \\
\text { PG across LVOT }\end{array}$ \\
\hline
\end{tabular}

CABG coronary artery bypass graft, $C C U$ coronary care unit, $C T$ computed tomography, ER emergency room, LVOT left ventricular outflow tract, $P G$ pressure gradient, TEE transesophageal echocardiography, TTE transthoracic echocardiography 
LVOT obstruction. Other LVOT masses that might cause obstruction include: myxoma, papillary fibroelastoma, and thrombus or vegetations, which can produce similar echocardiographic appearances. However, a detailed TTE and TEE can be used to differentiate them from AMVT [9]. Both TTE and TEE may help in the diagnosis, revealing possible associated lesions and complications [10]. Regarding treatment of this anomaly, cardiac surgery is indicated only in patients with significant LVOT gradients and those undergoing correction of other congenital cardiac defects in childhood or acquired disease if an adult. Surgery includes accessory tissue removal and, sometimes, artificial chordae implantation and annuloplasty, depending on the severity of the disease [11-13].

\section{Conclusion}

Echocardiography is considered to be the cornerstone investigation tool when assessing an aortic valve stenosis regardless of the cause. Significant LVOT obstruction happens when the PG exceeds $50 \mathrm{mmHg}$ through LVOT flow and surgery is the only treatment in this severe status. However, conservative therapy is indicated for PG less than $50 \mathrm{mmHg}$ except when the lesion is associated with other congenital defects. Finally, when facing such a case in the future, it is recommended to make a more rapid surgical response.

\section{Additional files}

Additional file 1: Video S1. Transthoracic echocardiography demonstrated left ventricle output obstruction caused by a mobile mass. (MP4 $421 \mathrm{~kb})$

Additional file 2: Video S2. Transesophageal echocardiography showed the anatomical relation of the accessory tissue and the anterior leaflet of the mitral valve. (MP4 $3570 \mathrm{~kb}$ )

\section{Abbreviations \\ AMVT: Accessory mitral valve tissue; bpm: Beats per minute; CABG: Coronary artery bypass graft; CX: Circumflex; LAD: Left anterior descending; LVOT: Left ventricular outflow tract; MS-CT: Multi-slice computed tomography; PG: Pressure gradient; RCA: Right coronary artery; TEE: Transesophageal echocardiography; TTE: Transthoracic echocardiography}

\section{Acknowledgements}

The authors are grateful to Dr Antoine Nasimian, MD (Radiologist of Aleppo University Hospital, Aleppo, Syria) for his assistance to our study.

\section{Funding}

N/A.

\section{Availability of data and materials}

All data generated or analyzed during this study are included in this published article and its supplementary information files.

\section{Authors' contributions}

MM was responsible for critical revision of the manuscript for content and supervision. AS was responsible for conception, design, acquisition, and interpretation of data. HA was responsible for surgical treatment. AB was responsible for doing echocardiography and follow up. All authors reviewed and contributed to the final version of this case report. All authors read and approved the final manuscript.

\section{Ethics approval and consent to participate}

No ethical approval was required in our institution for a case report involving a single patient.

\section{Consent for publication}

Written informed consent was obtained from the patient for publication of this case report and any accompanying images. A copy of the written consent is available for review by the Editor-in-Chief of this journal.

\section{Competing interests}

The authors declare that they have no competing interests.

\section{Publisher's Note}

Springer Nature remains neutral with regard to jurisdictional claims in published maps and institutional affiliations.

\section{Author details}

${ }^{1}$ Cardiology Department, Aleppo University Hospital, Aleppo, Syria. ${ }^{2}$ Cardiac Surgery Department, Aleppo University Hospital, Aleppo, Syria.

${ }^{3}$ Echocardiography Department, Aleppo University Hospital, Aleppo, Syria.

Received: 26 October 2018 Accepted: 1 May 2019

Published online: 17 June 2019

\section{References}

1. Prifti $E$, Bonacchi M, Bartolozzi F, Frati G, Leacche M, Vanini V. Postoperative outcome in patients with accessory mitral valve tissue. Med Sci Monit. 2003:9:126-33.

2. Rovner A, Thanigaraj S, Perez JE. Accessory mitral valve in an adult population: the role of echocardiography in diagnosis and management. J Am Soc Echocardiography. 2005;18:494-8.

3. Chevers N. Observations on diseases of the orifice and valves of the aorta. Guy's Hospital Reports. 1842;7:387-452.

4. MacLean LD. Subaortic stenosis due to accessory tissue on the mitral valve. J Thorac Cardiovasc Surg. 1963:45:382-7.

5. Yuan S, Shinfeld A, Mishaly D, Haizler R, Ghosh P, Raanani. E. Accessory mitral valve tissue: a case report and an updated review of literature. J Card Surg. 2008;(23):769-72.

6. Uslu N, Gorgulu S, Yildirim A, Eren M. Accessory mitral valve tissue: report of two asymptomatic cases. Cardiology. 2006;(105):155-7.

7. Prifti E, Frati G, Bonacchi M, Vanini V, Chauvaud S. Accessory mitral valve tissue causing left ventricular outflow tract obstruction: case reports and literature review. J Heart Valve Dis. 2001;10:774-8.

8. Rozo JC, Medina D, Guerrero C, Calderon AM, Mesa A. Accessory mitral valve without left ventricular outflow tract obstruction in an adult. Tex Heart Inst J. 2008:35:324-6.

9. W W LX, Wang L, Sun $X$, Jiang $Y$, Huo S, et al. The accuracy of echocardiography versus surgical and pathological classification of patients with ruptured mitral chordae tendinae: a large study in a Chinese cardiovascular center. Cardiothorac Surg. 2011;6:94.

10. Sharma R, Smith J, Elliott PM, Mckenna WJ, Pellerin D. Left ventricular outflow tract obstruction caused by accessory mitral valve tissue. J Am Soc Echocardiography. 2006;19:354.

11. Panduranga P, Eapen T, Al-Maskari S, Al-Farqani A. Accessory mitral valve tissue causing severe left ventricular outflow tract obstruction in a postSenning patient with transposition of the great arteries. Heart Int. 2011;6:6.

12. D'Aloia A, Vizzardi E, Chiari E, Fracassi F, Zanini G, Faggiano P, et al. Dynamic mild subaortic left ventricular obstruction caused by an accessory mitral valve attached to the anterior mitral valve in a young pregnant woman. Eur J Echocardiography. 2008;9:160-1.

13. Manganaro R, Zito C, Khandheria BK, Cusmà-Piccione M, Todaro MC, Oreto $G$, et al. Accessory mitral valve tissue: an updated review of the literature. EHJ Cardiovascular Imaging. 2014;15:489-97. 